\title{
China, Hong Kong, and Taiwan: \\ A Quantitative Assessment of Real and Financial Integration*
}

\author{
Yin-Wong CHEUNG, University of California, Santa Cruz \\ Menzie D. CHINN, University of California, Santa Cruz and NBER
}

Eiji FUJII, University of Tsukuba, Japan

\begin{abstract}
The status of real and financial integration of China, Hong Kong, and Taiwan is investigated using monthly data on one-month interbank rates, exchange rates, and prices. Specifically, the degree of integration is assessed based on the empirical validity of real interest parity, uncovered interest parity, and relative purchasing power parity. There is evidence these parity conditions tend to hold over longer periods, although they do not hold instantaneously. Overall, the magnitude of deviations from the parity conditions is shrinking over time. In particular, China and Hong Kong appear to have experienced significant increases in integration during the sample period. It is also found that exchange rate variability plays a major role in determining the variability of deviations from these parity conditions.
\end{abstract}

Key words: uncovered interest parity, real interest parity, purchasing power parity, exchange rates, capital mobility, market integration

JEL classification: F31, F41

Address for Correspondence: Yin-Wong Cheung, Economics Department, SS1, University of California, Santa Cruz, CA 95064, U.S.A. Email - cheung@,cats.ucsc.edu. Tel/Fax: +1 (831) 459-4247/5900.

* The authors thank Mike Devereux, Charles Engel, Stefan Gerlach, Paul De Grauwe, Jimmy Ha, Jim Malley, Elliott Parker, Joseph Plasmans, Frank Westermann, Ka-Fu Wong, and participants of the 2002 "WTO, China and the Asian Economies" conference, the 2003 "Area Conference On Macro, Money \& International Finance," and the Hong Kong Institute for Monetary Research seminar for their comments and suggestions. Also, we thank Desmond Hou for compiling the data. The financial support of faculty research funds of the University of California, Santa Cruz is gratefully acknowledged. The views contained herein are solely those of the authors, and do not necessarily represent those of the institutions they are associated with. 


\section{Introduction}

The recent accession of China to the WTO has been heralded as a watershed event, marking a distinct break in China's economic relations with the rest of the world. Analyses focused on WTO effects include Chang et al. (2001), Wang (2001), Ma (2001) and articles in the winter 2001 issue of China Economic Review. Doubtless, the commitment of China to abide by international norms in trade in goods and services will cause a substantial change in the way the Chinese economy behaves. We believe that this event, important as it is, should be viewed in the wider context as a continuing process of economic integration of China with its neighbors. However, previous quantitative analyses have been mostly focused on sectoral/trade issues. Some empirical studies of trade linkages are Wei et al. (2000), Noland et al. (1998), and Fernald et al. (1999). More recently, Poncet (2003) uses trade flow data to assess and compare the degrees of economic integration between a) Chinese provinces and b) Chinese provinces and the rest of the world. A thoroughgoing investigation -- corresponding to the many exhaustive studies of the financial and real links between East Asian countries -- is notably lacking. ${ }^{1}$

Since its recent economic reform, China has been embarked upon a process of financial and real integration with Hong Kong and Taiwan. Even before Hong Kong's return to China's sovereignty in 1997, it had achieved a high degree of integration with the mainland. With respect to trade, for instance, Hong Kong intermediates the lion's share of China's external trade via reexports and offshore trade. Regarding financial activity, a substantial amount of international

1 On financial/monetary issues, see Cheung, He and $\mathrm{Ng}$ (1994), Glick and Hutchison (1990), Chinn and Frankel (1994, 1995), De Brouwer (1999), Tsang (2002) and in the post-Crisis era, Kumhof (2001). In terms of real exchange rates, see most recently Cheung and Lai (1998), Chinn (2000), Fujii (2002), and Fukuda and Kano (1997). 
capital (in the forms of foreign direct investment, equity and bond financing and syndicated loans) financing China's economic expansion is raised via Hong Kong. At the same time, Hong Kong's role as an intermediary for trade and financial flows to China represents a major source of economic activity and greatly shapes its own economic structure. The deflationary pressure exerted by China on the Hong Kong price level is a manifestation of the close ties between the two economies. ${ }^{2}$

Perhaps more surprising to a casual observer, despite political and ideological differences and occasional tensions between China and Taiwan, economic links between these two economies have proliferated since the 1990s. According to official statistics, China is the largest recipient of Taiwan's overseas investment and Taiwan is China's third-largest source of foreign direct investment. Furthermore, it is widely believed that the official statistics under-represent the overall Taiwan economic interest in China. Some analysts count Taiwan's total investment in China as just behind that of Hong Kong's but ahead of that of the US. Even without direct trade, the trade volume between these two economies has grown two times or ten times, depending on the data sources, in the 1990s. ${ }^{3}$ Given current trends, it is likely that China will surpass the US and become Taiwan's largest export market by the end of 2002 (Ma, Zhu and Kwok, 2002).

2 Ha and Fan (2002) and Shellekens (2002) study the interactions of prices in China and Hong Kong and the deflationary effect on Hong Kong.

3 Because of trade restrictions and other political reasons, the official data from China, Taiwan and Hong Kong on trade between China and Taiwan are usually perceived to be incomplete. For instance, the value (in billions of US dollars) of total trade between China and Taiwan is 5.8 in 1991 and 10.5 in 2001, according to Hong Kong customs (re-export) data, 0.6 in 
The integration process between these three economies that comprise what is often termed "Greater China" is proceeding more along de facto than de jure lines. While the development among the Greater China economies has often been remarked upon, we believe that up until this point the analyses examining the strengthening of ties between these economies have been of an essentially anecdotal nature. ${ }^{4}$ In this paper, we examine quantitative aspects of integration in the context of macroeconomic concerns and characterize the current and future scope for integration and macroeconomic management between the Greater China economies.

It is known that market integration has direct implications for the effectiveness of domestic stabilization policy. Thus, a comprehensive stocktaking will allow policy makers to assess the spillover effects of macroeconomic policies among these economies, even as their combined importance in the world economy increases. To put these concerns into concrete form, consider the recent proposals for exchange rate management or coordination in East Asia, in scenarios that often include China and Hong Kong. The degree to which nominal exchange rates can be managed, according to theory, depends critically upon (1) how open capital markets are, and (2) how substitutable government debt instruments are. Both of these issues are directly linked to the degree at which various sectors are integrated. More broadly, when policy-makers are concerned about the extent to which independent macroeconomic policies can be pursued,

1991 and 10.6 in 2001 according to Taiwanese customs data, and 4.2 in 1991 and 32.4 according to Chinese customs data.

4 One early exception is Wei and Frankel (1994), who provide an assessment of whether a Greater China trade bloc exists. 
not only do these aspects of financial market integration matter, but so too do measures of real market integration. ${ }^{5}$

The focus of this study is to examine real interest parity, uncovered interest parity, and purchasing power parity. These three parity conditions define the key links between markets and are cornerstones of models in international finance. They are closely examined and routinely used as a gauge of the degree of integration in capital, financial, and goods markets. The real interest parity condition hinges on capital mobility and whether capital flows equalize real interest rates across economies. It can be shown that the degree to which real interest rate parity holds depends on the extent to which uncovered interest parity and relative purchasing power parity apply. Since uncovered interest parity involves financial arbitrage between money and foreign exchange markets and relative purchasing power parity entails arbitrage in goods and services, the real interest parity condition encompasses elements of both real and financial integration.

The plan of the paper is as follows. In section 2, we lay out a framework for systematically analyzing the components of financial and real integration. That is, we describe how deviations from real interest parity can be decomposed into two factors - uncovered interest parity deviations and deviations from relative purchasing power parity. In section 3 , we turn to examining each of these three factors, in terms of their stationarity characteristics, persistence, and trends. The compositions of deviations from the parity conditions are also studied in the same section. Some concluding remarks are offered in Section 4.

\section{A Framework for Analyzing Integration}

5 See Xu (2000) for a discussion of these factors in the Chinese context. 
The real interest parity, uncovered interest parity, and purchasing power parity conditions are the three pillars in international finance. Various approaches and datasets have been used to examine each of these parity conditions. Among the three conditions, purchasing power parity is perhaps the most intensively tested condition. Besides the question of whether these parity conditions offer an adequate description of data, these conditions are commonly used to infer the linkages and the degree of market integration. In the following subsection, we outline the relationship between these parity conditions. Readers who are familiar with the parity conditions should skip this section and go directly to Section 3.

\subsection{An Accounting Identity}

Consider the ex ante real interest differential between two economies:

$$
r_{t, k}^{e}-r_{t, k}^{* e} \equiv\left(i_{t, k}-\pi_{t, k}^{e}\right)-\left(i_{t, k}^{*}-\pi_{t, k}^{* e}\right)
$$

where $r_{t, k}^{e}$ is the expected k-period real interest rate in the first economy with the "e" and " $\mathrm{k}$ " indicate the variable is expected and the maturity of the debt instrument. The "*” denotes the variables for the second economy. The real interest rate is given by the difference between $i_{t, k}$, the k-period nominal interest rate, and $\pi_{t, k}^{e}$, the expected inflation rate in k-periods. Hence, equation (1) defines the ex ante real rate as the nominal interest rate on an asset of maturity $\mathrm{k}$ periods, deflated by the inflation rate expected at time $t$ to prevail over the period $t$ to $t+k$ (annualized). ${ }^{6}$ The expected inflation is defined by

\footnotetext{
6 In this case, we are assuming that the interest rates are on highly liquid, money market instruments of identical default risk characteristics. Hence, we do not address default risk premia in our discussion.
} 


$$
\pi_{t, k}^{e} \equiv p_{t, k}^{e}-p_{t}
$$

where $p_{t, k}^{e}$ and $p_{t}$ are, respectively, the price (in $\log$ ) expected to prevail at $\mathrm{t}+\mathrm{k}$ and the price at

t. The expected inflation in the second economy is similarly defined

$$
\pi_{t, k}^{*_{e}} \equiv p_{t, k}^{* e}-p_{t}^{*}
$$

The expression for the real interest differential on the right hand side of (1) can be rearranged, and expected depreciation subtracted and added, to yield:

$$
r_{t, k}^{e}-r_{t, k}^{* e} \equiv\left(i_{t, k}-i_{t, k}^{*}-\Delta s_{t, k}^{e}\right)-\left(\pi_{t, k}^{e}-\pi_{t, k}^{e^{*}}-\Delta s_{t, k}^{e}\right)
$$

where expected depreciation is given by:

$$
\Delta s_{t, k}^{e} \equiv s_{t, k}^{e}-s_{t}
$$

and $s_{t}$ is the exchange rate between monies in the two economies expressed in logarithm form. Note that the first term on the right hand side of (4) is the uncovered interest differential, and the second term is the deviation from ex ante relative purchasing power parity. The notion of purchasing power parity in (4) is different from the purchasing power parity commonly examined in the literature. In fact, the form of purchasing power parity embedded in the equivalence of parities is akin to the efficient market purchasing power parity introduced by Roll (1979), who show that under the efficient market assumption, ex ante deviations from purchasing power parity are unpredictable. Frankel (1991), for example, suggests that violation of ex ante relative purchasing power parity is associated with incomplete integration of goods markets. Thus, the purchasing power parity term used in the remaining part of the paper in should be properly interpreted as the Roll's notion of efficient market purchasing power parity or just ex ante relative purchasing power parity.

The uncovered interest differential can be further decomposed into: 


$$
\left(i_{t, k}-i_{t, k}^{*}-\Delta s_{t, k}^{e}\right) \equiv\left[i_{t, k}-i_{t, k}^{*}-\left(f_{t, k}-s_{t}\right)\right]+\left(f_{t, k}-s_{t, k}^{e}\right)
$$

where $f_{t, k}$ is the k-period forward rate, the term in square brackets is called covered interest differential, and the term $\left(f_{t, k}-s_{t, k}^{e}\right)$ is sometimes labeled risk premium. Ideally, in assessing the nature of the factors preventing parity conditions from holding, one would like to discriminate between covered interest differentials ${ }^{7}$ and the exchange risk premium. However, data limitations preclude us from doing so in this experiment. ${ }^{8}$ Hence, we will conduct the analysis keeping in mind that we impound the covered interest differential and the exchange risk premium into the uncovered interest differential.

\subsection{An Operational Framework}

Strictly speaking, real interest parity is an ex ante concept defined by expectations rather than realized real interest rates. The theoretical relationship between the three parity conditions is defined by identity (4). However, due to the paucity of data on expectations, the identity cannot be used to assess the empirical relevance of these parity conditions. Instead, we employ an operational version based on ex post differentials,

$$
r_{t, k}-r_{t, k}^{*} \equiv\left(i_{t, k}-i_{t, k}^{*}-\Delta s_{t, k}\right)-\left(\pi_{t, k}-\pi_{t, k}^{*}-\Delta s_{t, k}\right)
$$

7 The covered interest differential is sometimes termed political risk, associated with capital controls or the threat of their imposition. See Aliber (1973), Dooley and Isard (1980) and Frankel (1984) for applications.

8 In particular, we have only incomplete data on forward rates, and do not observe expected exchange rate changes. In Chinn and Frankel (1994), expectations are proxied with survey based data, which are unavailable to us for all these currencies. 
to examine the data from the three Greater China economies. One way to justify the use of (7) is that, under the rational expectations hypothesis, the ex post realizations are unbiased predictors of the ex ante counterparts. ${ }^{9}$

\subsection{Financial versus Real Integration}

Abstracting from the distinction between ex ante and ex post, equations (4) and (7) imply that a sufficient condition for real interest parity to hold is that both uncovered interest parity and relative purchasing power parity hold. On the other hand, one may observe real interest parity when both uncovered interest parity and relative purchasing power parity do not hold but their deviations happen to cancel each other out. Such a phenomenon can occur. For example, consider the case in which exchange rate movements are very volatile relative to movements in interest rates and inflation. Since the exchange rate change term appears in uncovered interest parity and relative purchasing power parity with opposite signs, the data appear to conform more closely to real interest parity than other two parity conditions. Such a possibility is examined in subsection 3.4 .

While uncovered interest parity pertains to financial integration driven by arbitrage between money and foreign exchange markets - that is how desirable currencies are viewed and how free money is to move - relative purchasing power parity pertains to how easily goods and services are arbitraged. Hence, real interest parity is a function of both financial and real market integration (Frankel, 1991). To make this assertion concrete, consider a situation where financial

9 In other words, we are equating the subjective market expectations with the conditional mathematical expectations, viz., $x_{t, k}^{e}=\mathrm{E}\left(x_{t, k} \mid \mathrm{I}_{\mathrm{t}}\right)$, in a steady state such that $x_{t, k}-\mathrm{E}\left(x_{t, k} \mid \mathrm{I}_{\mathrm{t}}\right)=\xi_{t, k}$ where $\xi_{t, k}$ is a true innovation. 
markets in two economies were well integrated, while differential inflation rates were not offset by changes in exchange rates. Then real interest differentials could persist not because financial capital flows were hindered and covered interest parity is violated, but because of the breakdown of relative purchasing power parity due to limited strength of the forces that drive together goods prices (expressed in a common currency).

The condition wherein real interest rate parity holds is sometimes termed real capital mobility. That is, real interest rates are equalized when "real" capital is free to move. To see why some observers make this equivalence, consider the basic microeconomic theory. An optimizing firm sets the marginal product of capital equal to the user cost of capital. Absent taxes (and ignoring depreciation), the user cost of capital is nominal interest rate, adjusted by the rate of inflation of its output. Hence real interest parity is taken as a signal of the equalization of the marginal product of capital. ${ }^{10}$

\section{Empirical Results}

The data considered in this exercise are monthly observations on one-month interbank interest rates, exchange rates, and consumer price indexes for China, Hong Kong and Taiwan from February 1996 to June 2002. See the Data Appendix for a more detailed description. The period of analysis is dictated by data availability, and more importantly, by the realities of the liberalization process in China. A unified national interbank market was only established in January of 1996; prior to that the interbank market was substantially controlled (Xie, 2002).

10 There is a subtlety involved in using parity conditions to evaluate integration. When a parity condition is rejected, then enlargements and diminutions of deviations may be due to either greater economic integration, greater convergence of economic policies, or both. 
Hence, extending the interest rate series backwards would not yield more information relevant to assessing financial integration. ${ }^{11}$

For each pair of economies, the ex post real interest differential $\left(r_{t, k}-r_{t, k}^{*}\right)$, ex post uncovered interest differential $\left(i_{t, k}-i_{t, k}^{*}-\Delta s_{t, k}\right)$, and ex post relative purchasing power differential $\left(\pi_{t, k}-\pi_{t, k}^{*}-\Delta s_{t, k}\right)$ are constructed to examine the relevance of the parity conditions and assess the degree of integration between the Greater China economies. For notational simplicity, we drop the term "ex post" hereafter.

The three differential series, which are expressed in annualized percentages, are graphed in Figures 1 to 3. Table 1 presents some of their descriptive statistics. Several observations are in order. First, for the three series, the Hong Kong and China series has the smallest mean, range (maximum - minimum), variance, skewness, and kurtosis. If these numbers are used to assess integration, then Hong Kong and China appear to have a high level of integration. Second, the effects of the $1997 / 98$ crisis are not too obvious in the graphs of real interest differentials but are quite easy to identify in the Taiwan-China and Taiwan-Hong Kong series in Figures 2 and 3. It is likely that the effects of the crisis on uncovered interest and relative purchasing power differentials work in offsetting directions such that the combined effect on real interest differentials is mitigated.

11 There is a separate question of whether the one-month rate is representative of other short-term interest rates, including the commercial paper and repo rates. Li and Peng (2002) argue that in recent years the segmentation in these short-term instruments has largely disappeared. 
Third, other than the crisis effects and the Hong Kong-China uncovered interest differential series, the differential series appear to display some wide variations around the zero mark. According to the descriptive statistics in Table 1, the sample means of real interest differentials are not statistically different from zero. There is no significant evidence that the real interest rate differentials are systematically positive or negative. The uncovered interest differentials, on the other hand, are found to be significantly negative. The results, however, are likely to be an artifact of the crisis effect revealed in the graphs. In fact, when dummy variables are used to account for the crisis, the sample means of the uncovered interest differentials are substantially smaller and become insignificant. ${ }^{12}$ Similar results are found for the Taiwan-China and Taiwan-Hong Kong relative purchasing power differentials. The effects of crisis on these two series are quite obvious in Figure 3. When the crisis dummies are considered, the sample mean of the Taiwan-China relative purchasing power differentials drops from 5.43 to 1.18 and that of the Taiwan-Hong Kong series from 4.31 to -1.02 . Thus it is safe to assume that, ignoring the 1997 crisis effect, these differential series fluctuate widely around zero.

While there are a multitude of studies evaluating various parity conditions, few of them pertain specifically to these economies, and to exactly these differentials. One study that uses a decomposition similar to the one used here is de Brouwer (1999, p.92). For a set of East Asian economies, he finds mean three month real interest differentials with the U.S. ranging between $1.73 \%$ to $1.03 \%$ for the Philippines and Hong Kong respectively. ${ }^{13}$ While these values are not too dissimilar to those we find, the contrast is more pronounced for the uncovered interest and

12 Specifically, the sample means are -0.79 (Hong Kong and China), -2.34 (Taiwan and China), and -1.53 (Taiwan and Hong Kong) when the 1997 dummies are included.

13 De Brouwer examines a sample from as early as 1980:Q1 to as late as 1994:Q4. 
relative purchasing power differentials. Nowhere does de Brouwer identify mean differentials as large as we do; the largest in absolute value is for the Philippines (-1.97\%). A similar phenomenon prevails for relative purchasing power parity deviations. Of the emerging markets, Hong Kong exhibits the largest deviation, at $-0.98 \%$. This value is overshadowed by the $4-5 \%$ mean deviations registered for Taiwan/China and Taiwan/Hong Kong. These contrasting patterns are best viewed keeping in mind that the period examined by de Brouwer corresponded to one of pegged and highly managed exchange rates, while ours spans a period of extreme currency volatility, and this manifests itself in larger ex post deviations from uncovered interest parity and relative purchasing power parity. In the case of Hong Kong/China - effectively a pegged exchange rate regime - the pattern of deviations is similar to those pertaining to the earlier sample.

In the following subsections, we evaluate the parity conditions via a few perspectives. First, we test for the presence of a unit root in these differential series. Second, we assess the predictive ability of the past values of a differential series. Third, we examine whether the deviations from the parity condition are shrinking over time or not.

\subsection{Real Interest Parity}

In some earlier studies, regression methods are used to determine the validity of real interest parity (Cumby and Obsfeld, 1984). For example, interest rate differentials are regressed on inflation differentials and the coefficient estimates are used to assess whether the real interest rate parity condition holds. ${ }^{14}$ In this study, we use the concept of mean stationarity to evaluate

14 There is an extensive literature on testing real interest parity. See Mishkin (1984), Mark (1985), and Cumby and Mishkin (1986). In the literature, exact formulae for calculating interest 
the parity condition. If the deviations from ex post real interest parity are transitory and stationary, then even though the condition does not hold in the short run, deviations from parity are transitory. The argument follows from the property of a stationary time series - a stationary time series will revert back to its equilibrium value after being disturbed by external shocks. On the other hand, if the deviations from parity are not stationary, shocks can lead to permanent displacements from equilibrium and there is no built-in mechanism to restore the parity condition even in the long run. ${ }^{15}$ The use of the stationarity criterion is appropriate because a parity relation is usually established under some ideal conditions that are unlikely to hold in short run. The use of stationarity tests can also be rationalized by recalling that we only observe ex post inflation and depreciation rates; hence it makes no sense to assume that the ex post parity conditions hold instantaneously. As long as the parity conditions hold ex ante and the expectations errors are mean stationary, tests for stationarity will be informative.

A modified Dickey-Fuller test known as the ADF-GLS test (Elliott, Rothenberg, Stock, 1996) is used to test for stationarity. While the standard Dickey-Fuller procedure is notorious for its low power, the ADF-GLS test is shown to be approximately uniformly most powerful invariant. Consider a series $\left\{q_{t}\right\} ; q_{t}=$ real interest differential, uncovered interest differential,

rate variables (instead of log approximations) are typically used in the context of testing for real interest parity. However, it is noted that data derived from exact formulae and log approximations gave qualitatively similar test results. Following the general practice, the test results in Tables 2 to 4 are based on the exact formula convention.

15 The constant associated with the real interest parity deviation can be interpreted as a time-invariant difference in the default risk or liquidity attributes of the money market instruments that have been assumed away in the algebraic expressions. 
and relative purchasing power differential. The ADF-GLS ${ }^{\tau}$ test that allows for a linear time trend is based on the following regression:

$$
(1-L) q_{t}^{\tau}=\alpha_{0} q_{t-1}^{\tau}+\sum_{k=1}^{p} \alpha_{k}(1-L) q_{t-k}^{\tau}+\varepsilon_{t}
$$

where $q_{t}^{\tau}$ is the locally detrended process under the local alternative of $\bar{\alpha}$ and is given by

$$
q_{t}^{\tau}=q_{t}-\tilde{\gamma}^{\prime} z_{t}
$$

with $z_{t}=(1, t)^{\prime} \cdot \widetilde{\gamma}$ is the least squares regression coefficient of $\widetilde{q}_{t}$ on $\widetilde{z}_{t}$, where $\left(\widetilde{q}_{1}, \widetilde{q}_{2} \ldots \ldots . \widetilde{q}_{T}\right)=$ $\left(q_{1},(1-\bar{\alpha} L) q_{2}, \ldots,(1-\bar{\alpha} L) q_{T}\right),\left(\widetilde{z}_{1}, \widetilde{z}_{2} \ldots \ldots \widetilde{z}_{T}\right)=\left(z_{1},(1-\bar{\alpha} L) z_{2}, \ldots,(1-\bar{\alpha} L) z_{T}\right)$, and $L$ is the lag operator. The local alternative $\bar{\alpha}$ is defined by $\bar{\alpha}=1+\bar{c} / \mathrm{T}$ for which $\bar{c}$ is set to -13.5 . The ADF-GLS $^{\mu}$ test, which allows for only an intercept, involves the same procedure as the ADFGLS $^{\tau}$ test, except that $q_{t}^{\tau}$ is replaced by the locally demeaned series $q_{t}^{\mu}$, which is obtained by setting $z_{t}=1$ and $\bar{c}$ to -7 . In implementing the test, the lag parameter $\mathrm{p}$ is chosen to make the error term $\varepsilon_{t}$ a white noise process. The unit root hypothesis is rejected when the ADF-GLS test statistic, which is given by the usual $t$-statistic for $a_{0}=0$ against the alternative of $a_{0}<0$, is significant. See Elliott, Rothenberg, Stock (1996) for a detailed description of the testing procedure.

The results of applying the ADF-GLS ${ }^{\tau}$ and ADF-GLS ${ }^{\mu}$ tests to the three real interest differential series are presented in Panel A of Table 2. For all the three series, the residual Qstatistics indicate that the selected lag specifications are quite adequate. Both the ADF-GLS ${ }^{\tau}$ and ADF-GLS ${ }^{\mu}$ test statistics are negative and significant; suggesting that the real interest differential series are stationary. That is, for the three Greater China economy pairs, the deviations from real interest parity are stationary and tend to disappear over time. The evidence is supportive of the 
presence of long-run real interest parity among the Greater China economies - that is, the real interest rates in the Greater China economies tend to converge in the long run.

Panel B of Table 2 reports the results of the following regression

$$
q_{t}=\alpha_{0}+\sum_{k=1}^{p} \alpha_{k} q_{t-k}+\varepsilon_{t} .
$$

The regression is used in some previous studies assessing the parity condition. Under instantaneous real interest parity, the expected real interest differential is random, has a zero mean, and cannot be predicted by available information. Thus, the significance of $\alpha_{k}$ 's in (1) is considered as evidence against the validity of the (instantaneous) parity condition.

As reported in Panel B, the real interest differentials between Hong Kong and China and between Taiwan and China display significant persistence. That is, for these two cases, the deviation from the real interest parity is predictable and the markets are not efficient in this sense. The explained component, as indicated by the adjusted- $\mathrm{R}^{2}$, ranges from $12 \%$ of the Hong Kong-China real interest differentials to $19 \%$ of the Taiwan-China differentials. The coefficients on the lagged real interest differentials between Taiwan and Hong Kong are not significant. The results indicate that there is less integration of China with the other two economies. This finding is not surprising because, among the greater China economies, China has the strictest controls on trade and financial flows. Despite the limited extent of integration and the failure of short-run real interest parity, the stationarity results in Panel A suggest that the real interest rates in these economies tend to converge.

Even though integration is incomplete, it does appear to be fairly high. The sum of the significant AR coefficients is approximately 0.5 . In contrast, Holmes (2002) reports that the corresponding panel coefficient for Belgium, France, and the Netherlands against Germany is about 0.75 over the $1993-98$ period. 
Next, we use a simple panel setting to reveal the possible trending behavior of dis-parity. Specifically, we would like to investigate whether the magnitude of deviation is diminishing during the sample period. To this end, we construct an annual measure of absolute deviation by averaging the monthly absolute real interest differentials. For a given calendar year $t$ and economy-pair i, the annual absolute deviation is defined by

$$
\widetilde{q}_{i, t}=12^{-1} \sum_{k=1}^{12} a b s\left(q_{i, t, k}\right)
$$

where $\operatorname{abs}\left(q_{i, t, k}\right)$ is the absolute value of the i-th economy-pair's k-th month real interest rate differential during year $\mathrm{t}, \mathrm{i}=$ Hong Kong-China, Taiwan-China and Taiwan-Hong Kong, and $\mathrm{t}=$ $1996, \ldots, 2001 .{ }^{16}$ The result of estimating the trend term in the panel regression

$$
\widetilde{q}_{i, t}=\alpha_{i}+\beta t+\varepsilon_{i, t}
$$

are reported in Table 2, Panel C. The economy-pair specific intercept term $\alpha_{i}$ allows individual absolute deviation series to have different means. The common trend term is significant at -0.65 ; indicating that, on the average, the magnitude of the deviation from the parity condition is declining during the sample period. ${ }^{17}$

Since the three Greater China economies are at different stages of reform and liberalization processes, it is useful to identify which economy is the major source of the general decline in the absolute deviation from real interest parity. We re-estimated (12) with individual economy-pair specific trend terms and reported the results in Panel C. The sign of the coefficient

16 The year 2002 is excluded because we have only 6 observations for that year.

17 The negative trend term should properly be interpreted as a description of in-sample behavior that does not necessarily extend beyond the sample period. Otherwise, one has to deal with the issue of a "negative" absolute deviation. 
estimates indicates that the real interest rate gaps tend to decline over time. The gaps between China and the other two economies exhibit a smaller decline during the sample. The three economy-pair specific trends are, nonetheless, not statistically significant. It is likely that the short sample period leads to the inconclusive statistical results. ${ }^{18}$

\subsection{Uncovered Interest Parity}

The real interest parity condition incorporates aspects of both real and financial integration. Although the results in the previous subsection are supportive of long-run real interest parity, it may be instructive to isolate the sources of rejection of short-run integration. To this end, we examine the cases of financial and real integration individually. The results related to financial integration between the three Greater China economies are given in Table 3, in a format analogous to that used in Table 2 .

Panel A presents the results of applying the unit root tests on the uncovered interest differential series. The unit root hypothesis is strongly rejected by both ADF-GLS ${ }^{\tau}$ and ADF$\mathrm{GLS}^{\mu}$ test statistics. That is, the uncovered interest differential series are stationary and shocks to the uncovered interest parity are transitory. Consistent with the real interest parity result, the data show that, among the Greater China economies, the uncovered interest rate parity holds in the long run.

The results of fitting uncovered interest differential to equation (10) are given in Panel B. The deviation from uncovered interest parity does not appear random for the Hong Kong-China

18 It is speculated that the extraordinary 1997 financial crisis makes it more difficult to discern the trending behavior. However, the inclusion of a 1997 (or 1998) dummy has no material impact on the trend estimates in Table 2 and the subsequent Tables 3 and 4. 
pair. For this case, the lagged uncovered interest differential variables are positively significant and indicative of strong persistence. The adjusted $-\mathrm{R}^{2}$ is quite high at the level of 0.62 . If monies are free to move across markets, arbitrage can generate profits based on the pattern of persistent deviation and help restore the parity. However, the observed persistent deviations are consistent with the capital controls prevailing in China, which make this kind of arbitrage activity quite difficult, especially in the short run. The results for the two cases involving Taiwan, on the other hand, suggest the deviations are quite random. The results between these three uncovered interest differential series are broadly in line with the degrees of financial liberalization in these economies.

We used the annual absolute deviation from uncovered interest parity, which is constructed in the same manner as the absolute deviation from real interest parity (see equation (10)), to assess the trending behavior of uncovered interest dis-parity. All the estimated common and economy-pair specific time trends have a negative sign - indicating the differentials are narrowing during the sample. However, only the estimate of Hong Kong-China pair is statistically significant. The other estimates are larger (in absolute value) but have an even larger standard error. ${ }^{19}$

19 During the sample period, both Hong Kong and China have their currencies effectively pegged to the US dollar. Thus, the Hong Kong and China exchange rate is relatively stable and contributes little to the Hong Kong and China uncovered interest differential. For the other two cases, the exchange rate change dominates the relative interest rate and makes the uncovered interest differentials much more volatile. This may be the reason why the Hong Kong and China trend estimate is smaller (in absolute value) but significant. 


\subsection{Relative Purchasing Power Parity}

The three relative purchasing power differential series are used to assess the real integration between the three Greater China economies. The empirical results are presented in Table 4. The ADF-GLS ${ }^{\tau}$ and ADF-GLS ${ }^{\mu}$ tests strongly reject the presence of a unit root in these differential series. While the stationarity result is expected from the identity (7) and the results in the previous two subsections, it is comforting to see the unit root hypothesis is rejected by the actual data. Thus, there is evidence of real integration between the three economies in the long run.

The results in Panel B are quite different from the corresponding panels in the two preceding tables. The coefficient estimates of the lagged deviation from relative purchasing power parity are small and insignificantly different from zero. If the information set is restricted to lagged relative purchasing power parity deviations, $\left(\pi_{t, k}-\pi_{t, k}^{*}-\Delta s_{t, k}\right)$ is a random series. The result is supportive of the Roll's (1979) efficient markets purchasing power parity, which postulates $\left\{\pi_{t, k}^{e}-\pi_{t, k}^{e^{*}}-\Delta s_{t, k}^{e}\right\}$ is a zero mean random series.

There is no evidence of a decrease in the magnitude of relative purchasing power deviations revealed in Panel $\mathrm{C}$ of Table 4. The results are based on fitting absolute relative purchasing power differentials to equation (12). Both types of time trend, common and economy-pair specific, are not significant. Again, the results are in contrast with the corresponding ones in Tables 2 and 3, which find substantial evidence of diminishing deviation from the two interest parities. Note, however, that China opened its goods and services markets, albeit in a gradual fashion, long before launching financial reforms in the late 1990s. It is possible that the magnitude of relative purchasing power deviations declined before the current sample period and, hence, does not manifest itself in a declining trend in recent years. 
To entertain the possibility that the real integration has occurred before 1996, we repeated the exercise using monthly data from January 1984 to June 2002. For the extended sample, the common trend estimate is -0.334 with a standard error 0.172 . This result implies that, for the extended sample, the magnitude of relative purchasing power deviations is decreasing. For the economy-pair specific time trends, only the two for the pairs involving Hong Kong are negative and statistical significance. The estimate of the Hong Kong-China pair time trend is -1.037 (standard error 0.264). The results are consistent with the observation that, due to its special political and economic status, Hong Kong is better positioned to integrate with China. Overall, results pertaining to the extended sample and those in Table 4 suggest that there is considerable evidence of financial and real integration between Hong Kong and China.

The results of testing the parity conditions are summarized in Table $5 .{ }^{20}$ All in all, there is evidence that the three parity conditions hold in the long run. The unit root null is rejected for all the series and, thus, the deviations from these parities are stationary. Given the short sample considered and the usual concern about the power of unit root tests, the evidence in favor of the three long-run parity conditions is quite strong. Further, it appears that real integration between the three economies has progressed further than financial integration. The empirical finding is in accordance with the casual observation that, during their reform and liberalization processes, both China and Taiwan tend to open up their markets on goods and services before lightening their grasp on their financial sectors. ${ }^{21}$

20 We thank Ka-Fu Wong for suggesting the summary table.

21 Note that we are equating real integration with relative purchasing power parity holding. Given the difficulties in comparing widely differing consumption baskets, we do not refer to absolute purchasing power parity in levels for measuring goods market integration. 


\subsection{The Composition of Deviations from Parity Conditions}

The variance of a differential series provides a measure of the extent of deviation from a parity condition. For example, consider real interest parity. If the parity condition holds instantaneously, then the real interest differential series will be identically equal to zero. If the parity is subject to large shocks, then the variance of the differential series is large. Thus, a large differential variance is indicative of substantial deviation from the parity condition. An obvious caveat is that a constant deviation from the parity yields a zero variance for the differential series. While a constant deviation from the parity is rarely observed in data, the caveat raises the possibility that, due to impediments to capital flows including formal barriers and transaction costs, the parity condition may not hold exactly in reality. The impediments can create a zone in which it is not feasible for arbitrage to restore the parity. Under such circumstances, the observed differential series does not have a zero mean and its variance can be interpreted as a measure of deviation from parity allowing for the effect of impediments to capital flows.

The use of the variance of differential series offers a direct way to assess the components of dis-parity. In the case of real interest parity, the variance of real interest differential can be equivalently written as

$$
\begin{aligned}
\operatorname{Var}\left(r_{t, k}-r_{t, k}^{*}\right) \equiv & \operatorname{Var}\left(i_{t, k}-i_{t, k}^{*}-\Delta s_{t, k}\right)+\operatorname{Var}\left(\pi_{t, k}-\pi_{t, k}^{*}-\Delta s_{t, k}\right) \\
& -2 \operatorname{Cov}\left(i_{t, k}-i_{t, k}^{*}-\Delta s_{t, k}, \pi_{t, k}-\pi_{t, k}^{*}-\Delta s_{t, k}\right) .
\end{aligned}
$$

The intensity of deviation from real interest parity depends on the extents of financial and real dis-integration and the comovement between deviations from uncovered interest parity and relative purchasing power parity. The decomposition of $\operatorname{Var}\left(r_{t, k}-r_{t, k}^{*}\right)$ using actual data can 
pinpoint whether it is the barriers in financial markets or in goods markets that cause the failure to equalize real interest rates.

By the same token, the variances of uncovered interest and relative purchasing power differentials can be expressed as

$$
\operatorname{Var}\left(i_{t, k}-i_{t, k}^{*}-\Delta s_{t, k}\right) \equiv \operatorname{Var}\left(i_{t, k}-i_{t, k}^{*}\right)+\operatorname{Var}\left(\Delta s_{t, k}\right)-2 \operatorname{Cov}\left(i_{t, k}-i_{t, k}^{*}, \Delta s_{t, k}\right)
$$

and

$$
\operatorname{Var}\left(\pi_{t, k}-\pi_{t, k}^{*}-\Delta s_{t, k}\right) \equiv \operatorname{Var}\left(\pi_{t, k}-\pi_{t, k}^{*}\right)+\operatorname{Var}\left(\Delta s_{t, k}\right)-2 \operatorname{Cov}\left(\pi_{t, k}-\pi_{t, k}^{*}, \Delta s_{t, k}\right)
$$

Using equations (14) and (15), we can assess the relative roles of nominal interest rates, exchange rate changes, relative inflation rates, and their comovements on deviations from the financial and real parity conditions.

The decomposition results based on (13) are presented in Table 6. The real interest differential between Hong Kong and China has the smallest variance while the one between Taiwan and Hong Kong has the largest variance. The relative contributions of uncovered interest dis-parity and relative purchasing power dis-parity are quite different across the three economypairs. For the Hong Kong-China real interest differential, $66.7 \%$ of the variation is attributable to relative purchasing power variability and $16.7 \%$ to uncovered interest variability. For the other two cases, both relative purchasing power variability and uncovered interest variability are much larger than the variance of real interest differentials. It is the negative comovement between relative purchasing power and uncovered interest differentials that keeps the variance of real interest differentials in check.

The results of the decomposition reflect the exchange rate arrangements of these economies. During the sample period, both Hong Kong and China effectively pegged their currencies to the US dollar while the Taiwan-US exchange rate is, relatively speaking, more 
flexible. Thus, the change in the Hong Kong-China exchange rate is relatively stable while those involving the New Taiwan dollar are more volatile. Thus, the variance of real interest differentials between Hong Kong and China is smaller than those of differentials involving Taiwan. Further, the uncovered interest and relative purchasing power differentials have a common exchange rate term. For the differential series involving Taiwan, the common exchange rate term dominates the temporal dynamics and produces a large negative covariance term. However, it is interesting to observe that, in the absence of substantial exchange rate volatility, the relative purchasing power component contributes mostly to the variance of real interest rate differential between Hong Kong and China.

The decomposition results for uncovered interest and relative purchasing power differentials are reported in Tables 7 and 8. In both cases, the variances of the Hong Kong-China pair differential series are substantially smaller than the other two pairs. The differences in variances and their compositions can be, again, traced to exchange rate arrangements. For the Hong Kong-China pair, the variance of exchange rate changes contributes less than $4 \%$ to the variations in uncovered interest differentials and relative purchasing power differentials. On the other hand, for the other four series involve Taiwan, the variance of exchange rate changes accounts for $73 \%$ to $101 \%$ of the uncovered interest and relative purchasing power differential variances. Since in all the cases in Tables 7 and 8 the covariance term account for a small percentage of the variance of dis-parity, the differences between variances across economy-pairs and their compositions are mainly due to the differences in exchange rate variability among these economies.

\section{Concluding Remarks}


China's role in the world economy has entered into a new phase, with its accession to the WTO. Up until this point, despite its growing economic importance and increasing trade and financial ties with other countries, China has been perceived to be a rather distinct market, with a limited degree of integration with the world economy. The theme of the current exercise is to study the degree of integration within Greater China, which includes China, Hong Kong, and Taiwan, thereby determining whether this perception has been accurate. Economic theory provides a number of criteria to evaluate the degree of market integration. We consider three parity conditions in this exercise. They include real interest parity as an indicator of "real" capital mobility, uncovered interest parities for assessing financial capital mobility, and deviations from relative purchasing power parity for measuring goods market integration.

In spite of the fact that China and Taiwan have implemented different types of trade barriers and capital controls, it is found that, to varying degrees, the long-run version of the three parity conditions hold among the Greater China economies. Hence, there is evidence of real and financial integration of these economies. On the other hand, the data do not in general satisfy the short-run parity conditions and we can conclude that the markets are not completely efficient.

During the sample period, China and Hong Kong appear to experience increasing real and financial integration while Hong Kong and Taiwan show no substantial gain in the integration process. Further, the evidence indicates the integration of markets for goods and services is stronger than that for financial assets. Exchange rate movements play a major role in determining the variability of deviations from these parity conditions. Among the three economy-pairs, China and Hong Kong has the least variable exchange rate (because of their de facto exchange rate arrangements with the US dollar) and the lowest variability of deviations from the three parity conditions under examination. 
Compared with the other two parity conditions, perturbations to relative purchasing power parity are small. Apparently, asymmetric real shocks are not an important factor over the sample period. ${ }^{22}$ However, the relatively small size of the relative purchasing power parity perturbations is a function of, say, the exchange rate regime China has maintained since 1994. As China moves toward convertibility, it is likely that over the intermediate run, some form of managed float will likely be implemented. The variability of the deviations from relative purchasing power parity, and hence real interest parity, will likely depend on how China manages its macroeconomy, and in particular, how it deals with the contingent liabilities of the banking sector and the pension system.

In the current exercise, data on exchange rates, interest rates and prices are used to assess the degree of integration. However, it is recognized that the concept of integration is difficult to define and measure precisely. Other approaches to assess integration include a) measuring the trade linkages, b) comparing the expected yields on similar assets in different economies, and c) evaluating the correlation of (output) shocks across economies and the relative contributions of common and economy-specific shocks to output variations. While the pursuance of these alternative approaches is beyond the scope of this paper, it is our belief that these approaches can offer valuable and complementary insights on integration between the Greater China economies.

22 Even if real shocks have been fairly small over the sample period, there is no guarantee that this state of affairs will continue into the future. As evidenced by the 1992-93 EMU crises, large shocks can still derail monetary co-operation even when macroeconomic indicators are converging. Eichengreen (2002), for example, gives a skeptical view of East Asian monetary cooperation. 
Another interesting future research topic is to identify and investigate the factors that are driving the integration process.

Even though the statistical results offer some evidence of integration, we recognize that there are non-negligible restrictions on both physical and financial flows between the Greater China economies. With scheduled removal of barriers associated with joining the WTO, it is expected that the ascendant Chinese economy will be increasingly integrated with those of Hong Kong and Taiwan. We conjecture that the increasing degree of integration will make the costs associated with the remaining impediments to the free flow of goods and capital more obvious and costly. Hence, we envision this process of integration continuing, and to the extent that this process requires even more political engagement, we believe the prospects for cooperation along a variety of dimensions are promising. 


\section{Data Appendix}

The data are collected from four sources - Bloomberg Financial Services, CEIC database, International Financial Statistics, and the Hong Kong Monetary Authority. The monthly series retrieved from Bloomberg is the China one-month interbank offer rate. The monthly series retrieved from CEIC are the Hong Kong one-month interbank offer rate, the Taiwan one-month interbank offer rate, the Taiwan-US exchange rate, the Hong Kong consumer price index, and the Taiwan consumer price index. The Taiwan interest rate is the middle rate given by a simple average of the high and low rates. The monthly series from International Financial Statistics are dollar-based exchange rates of Hong Kong dollar and China yuan. The Hong Kong Monetary Authority provided the China consumer price series.

The sample period is from February 1996 to June 2002. The exchange rates between the Greater China economies were derived from their dollar-based exchange rates. The X-12 routine (with multiplicative factors on the levels) was used to seasonally adjust all the price series. The Japanese CPI series also had an adjustment for the imposition of new taxes in April 1997. 


\section{References}

Aliber, R. Z., 1973, The interest rate parity theorem: A reinterpretation, Journal of Political Economy 81, 1451-59.

Chang C., B. M. Fleisher \& E. Parker, 2001. The impact of China's entry into the WTO: Overview, China Economic Review 11, 319-322.

Cheung, Y.-W. \& K. S. Lai, 1995, Lag order and critical values of a modified Dickey-Fuller test, Oxford Bulletin of Economics and Statistics 57, 411-419.

Cheung, Y.-W., J. He \& L. Ng, 1994, Pacific Basin stock markets and real activity, Pacific-Basin Finance Journal 2, 349-373.

Cheung, Y.-W. \& K. S. Lai, 1998, Economic growth and trend stationarity in real exchange rates: Evidence from some fast-growing Asian countries, Pacific-Basin Finance Journal $6,61-76$.

Chinn, M., 2000, Before the fall: Were East Asian currencies overvalued?, Emerging Markets Review 1, 101-126.

Chinn, M. \& J. Frankel, 1994, Financial links around the Pacific Rim: 1982-1992, in R. Glick and M. Hutchison (editors), Exchange rate policy and interdependence: Perspective from the Pacific Basin (Cambridge: Cambridge University Press) 17-26.

Chinn, M. \& J. Frankel, 1995, Who drives real interest rates around the Pacific Rim: The US or Japan?, Journal of International Money and Finance 14, 801-821.

Cumby, R. E. \& F. S. Mishkin, 1986, The international linkage of real interest rates: The European-U.S. connection, Journal of International Money and Finance 5, 5-23.

Cumby, R.E. \& M. Obstfeld, 1984, International interest rate and price level linkages under flexible exchange rates: A review of recent evidence, in J. F. O. Bilson and R. C. Marston 
(editors) Exchange rate theory and practice (University of Chicago Press, Chicago, IL) $121-151$.

De Brouwer, G., 1999, Financial integration in East Asia (New York: Cambridge University Press).

Dooley, M. \& P. Isard, 1980, Capital controls, political risk, and deviations from interest-rate parity, Journal of Political Economy 88, 370-84.

Eichengreen, B., 2002, Whither monetary and financial cooperation in Asia?, paper presented at PECC Finance Forum Conference Issues and Prospects for Regional Cooperation for Financial Stability and Development (Honolulu, August 11-13).

Elliott, G., T. J. Rothenberg, \& J. H. Stock, 1996, Efficient tests for an autoregressive unit root, Econometrica 64, 813-836.

Fernald, J., H. Edison, \& P. Loungani, 1999, Was China the first domino? Assessing links between China and other Asian economies, Journal of International Money and Finance $18,515-535$.

Frankel, J., 1984, The Yen/Dollar agreement: Liberalizing Japanese capital markets, Policy Analyses in International Economics 9 (Washington, D.C.: Institute for International Economics).

Frankel, J., 1991, Quantifying international capital mobility, in D. Bernheim and J. Shoven (editors), National saving and economic performance (Chicago: University of Chicago Press) 227-260.

Fujii, E., 2002, Exchange rate and price adjustments in the aftermath of the Asian crisis, International Journal of Finance and Economics 7, 1-14. 
Fukuda, S.-I., \& T. Kano, 1997, International price linkage within a region: The case of East Asia, Journal of the Japanese and International Economies 11, 643-666.

Glick, R. \& M. Hutchison, 1990, Financial liberalization in the pacific basin: Implications for real interest rate linkages, Journal of the Japanese and International Economies 4, 36-48.

Ha, J. \& K. Fan, 2002, Price convergence between Hong Kong and the Mainland, Research Memorandum, Hong Kong Monetary Authority.

Holmes, M.J., 2002, Does long-run real interest parity hold among EU countries? Some new panel data evidence, Quarterly Review of Economics and Finance 42, 733-746.

Kumhof, M., 2001, International capital mobility in emerging markets: New evidence from daily data, Review of International Economics 9, 626-640.

Li, Y. \& X. Peng, 2002, The money market in China: Theory and practice, China and the World Economy 10, 3-10.

Ma, J., 2001, Quantifying the effect of China's WTO entry, Global Markets Research (Hong Kong: DeutscheBank, December).

Ma, J., W. Zhu \& A. Kwok, 2002, China-Taiwan economic integration, Global Markets Research (Hong Kong: DeutscheBank, September).

Mark, N., 1985, Some evidence on the international inequality of real interest rates, Journal of International Money and Finance 4, 189-208.

Mishkin, F. S., 1984, Are real interest rates equal across countries? An empirical investigation of international parity conditions, Journal of Finance 39, 1345-1357.

Noland, M., L.G. Liu, S. Robinson, \& Z. Wang, 1998, Global economic effects of the Asian currency devaluations, Policy Analyses in International Economics 56 (Washington, D.C.: Institute for International Economics). 
Poncet, S., 2003, Measuring Chinese domestic and international integration, China Economic Review, forthcoming.

Roll, R., 1979, Violations of purchasing power parity and their implications for efficient international commodity markets, in M. Sarnat and G.P. Szego (editors), International finance and trade (Ballinger Publishing: Cambridge, MA.) 133-176.

Shellekens, P., 2002, Deflation in Hong Kong, SAR, People's Republic of China - Hong Kong Special Administrative Region: Selected Issues, IMF Country Report 02/99 (IMF: Washington, DC, May).

Tsang, S.-K., 2002, Optimum currency area for Mainland China and Hong Kong? Empirical Tests, HKIMR Working Paper No.16/2002.

Wang, Z., 2001, The impact of China's WTO accession on patterns of world trade, Paper presented at ASSA Annual Meeting in Atlanta Georgia, January 4-6, 2002.

Wei, S.-J., \& J. Frankel, 1994, A ‘Greater China’ trade bloc?, China Economic Review 5, 179190.

Wei, S.-J., L.G. Liu, Z. Wang \& W. T. Woo, 2000, The China money puzzle: Will devaluation of the yuan help or hurt the Hong Kong dollar?, China Economic Review 11, 171-188.

Xie, D., 2002, Analysis of the development of China's money market, China and the World Economy 10, 29-37.

Xu, Y., 2000, China's exchange rate policy, China Economic Review 11, 262-277. 
Table 1. Descriptive Statistics

\begin{tabular}{lccc}
\hline & Hong Kong/China & Taiwan/China & Taiwan/Hong Kong \\
\hline A. Real interest differentials & & \\
Mean & -0.178 & -1.847 & -1.637 \\
Maximum & 21.260 & 19.427 & 24.903 \\
Minimum & -20.899 & -43.994 & -42.102 \\
Variance & 86.818 & 114.100 & 158.727 \\
& & & \\
B. Uncovered interest differentials & & \\
Mean & $-1.276^{* *}$ & $-7.274^{*}$ & $-5.950^{\#}$ \\
Maximum & 9.787 & 51.813 & 49.970 \\
Minimum & -9.150 & -160.383 & -159.022 \\
Variance & 14.349 & 714.270 & 692.786 \\
C. Deviations from relative purchasing power parity & \\
Mean & 1.097 & $5.426^{\#}$ & \\
Maximum & 22.701 & 166.622 & 183.925 \\
Minimum & -16.187 & -62.297 & -79.662 \\
Variance & 57.931 & 782.878 & 962.943 \\
\hline
\end{tabular}

Notes: The real interest differentials, uncovered interest differentials, and deviations from relative purchasing power parity are all annualized and measured in percentage terms. “**," “*," and " "\#" indicate that the sample mean is significantly different from zero at the 1,5 , and $10 \%$ levels, respectively. 
Table 2. Real Interest Differentials

\begin{tabular}{|c|c|c|c|}
\hline & Hong Kong/China & Taiwan/China & Taiwan/Hong Kong \\
\hline \multicolumn{4}{|c|}{ A. Unit root test statistics } \\
\hline ADF-GLS $\mu$ & $-3.626 *[3]$ & $-2.358 *[6]$ & $-6.012 *[2]$ \\
\hline $\mathrm{Q}(6)$ & 10.067 & 0.642 & 6.707 \\
\hline $\mathrm{Q}(12)$ & 17.192 & 3.967 & 15.482 \\
\hline ADF-GLS $\tau$ & $-7.187 *[1]$ & $-4.996 *[5]$ & $-6.613 *[2]$ \\
\hline$Q(6)$ & 8.442 & 10.574 & 3.879 \\
\hline $\mathrm{Q}(12)$ & 13.866 & 15.265 & 11.310 \\
\hline \multicolumn{4}{|l|}{ B. Persistence } \\
\hline $\operatorname{AR}(1)$ & $\begin{array}{c}0.270^{*} \\
(0.120)\end{array}$ & $\begin{array}{c}-0.231^{*} \\
(0.107)\end{array}$ & $\begin{array}{c}-0.158 \\
(0.116)\end{array}$ \\
\hline $\mathrm{AR}(2)$ & $\begin{array}{c}0.250^{*} \\
(0.121)\end{array}$ & $\begin{array}{l}-0.175 \\
(0.111)\end{array}$ & $\begin{array}{c}0.077 \\
(0.117)\end{array}$ \\
\hline $\operatorname{AR}(3)$ & $\begin{array}{c}-0.063 \\
(0.120)\end{array}$ & $\begin{array}{l}-0.053 \\
(0.113)\end{array}$ & - \\
\hline $\operatorname{AR}(4)$ & - & $\begin{array}{l}-0.001 \\
(0.113)\end{array}$ & - \\
\hline $\operatorname{AR}(5)$ & - & $\begin{array}{c}0.136 \\
(0.111)\end{array}$ & - \\
\hline $\operatorname{AR}(6)$ & - & $\begin{array}{c}0.420^{* *} \\
(0.108)\end{array}$ & - \\
\hline Adjusted $\mathrm{R}^{2}$ & 0.124 & 0.192 & 0.008 \\
\hline \multicolumn{4}{|c|}{ C. Trends in annual absolute averages } \\
\hline Individual & $\begin{array}{l}-0.484^{\#} \\
(0.208)\end{array}$ & $\begin{array}{l}-0.471 \\
(0.283)\end{array}$ & $\begin{array}{l}-0.985 \\
(0.514)\end{array}$ \\
\hline Common & & $\begin{array}{c}-0.647 * * \\
(0.193) \\
\end{array}$ & \\
\hline
\end{tabular}

Notes: Results related to the properties of real interest differentials are presented. The economypairs are labeled in the first row. Panel A gives the ADF-GLS ${ }^{\tau}$ and ADF-GLS ${ }^{\mu}$ unit root test results. Levels of significance are determined using finite sample critical values (Cheung and Lai, 1995). Figures in square brackets are lag parameters selected by the Bayesian information criterion. Q(6) and Q(12) are the Box-Ljung Q-statistics based on the first six and twelve autocorrelations of the estimated residuals. Panel B gives the persistence of real interest differentials estimated from equation (10). Panel $\mathrm{C}$ gives the common and economy-pair (individual) specific trend estimates of the annual average of absolute real interest differentials (equation (12)). Robust standard errors are reported in parentheses underneath coefficient estimates. Significance at the 1,5 and 10\% levels are indicated by “**," "“*," and "\#,” respectively. 
Table 3. Uncovered Interest Differentials

\begin{tabular}{|c|c|c|c|}
\hline & Hong Kong/China & Taiwan/China & Taiwan/Hong Kong \\
\hline \multicolumn{4}{|c|}{ A. Unit root test statistics } \\
\hline ADF-GLS $\mu$ & $-2.126^{*}[5]$ & $-7.019 *[1]$ & $-4.673 *[2]$ \\
\hline $\mathrm{Q}(6)$ & 5.554 & 10.304 & 9.343 \\
\hline $\mathrm{Q}(12)$ & 10.670 & 18.275 & 17.748 \\
\hline ADF-GLS $\tau$ & $-2.808^{\#}[2]$ & $-4.892 *[2]$ & $-4.841 *[2]$ \\
\hline Q(6) & 9.457 & 8.471 & 9.050 \\
\hline $\mathrm{Q}(12)$ & 17.473 & 18.375 & 18.237 \\
\hline \multicolumn{4}{|l|}{ B. Persistence } \\
\hline $\operatorname{AR}(1)$ & $0.429 * *$ & 0.189 & 0.151 \\
\hline $\operatorname{AR}(2)$ & $\begin{array}{c}(0.118) \\
0.137 \\
(0.129)\end{array}$ & $\begin{array}{c}(0.115) \\
-\end{array}$ & $\begin{array}{c}(0.117) \\
0.109 \\
(0.118)\end{array}$ \\
\hline $\operatorname{AR}(3)$ & $\begin{array}{c}0.070 \\
(0.130)\end{array}$ & - & - \\
\hline $\operatorname{AR}(4)$ & $\begin{array}{l}-0.073 \\
(0.129)\end{array}$ & - & - \\
\hline $\operatorname{AR}(5)$ & $\begin{array}{l}0.282^{*} \\
(0.115)\end{array}$ & - & - \\
\hline Adjusted $\mathrm{R}^{2}$ & 0.620 & 0.022 & 0.012 \\
\hline \multicolumn{4}{|c|}{ C. Trends in annual absolute averages } \\
\hline Individual & $\begin{array}{l}-0.950^{*} \\
(0.299)\end{array}$ & $\begin{array}{l}-1.760 \\
(2.448)\end{array}$ & $\begin{array}{l}-0.985 \\
(2.371)\end{array}$ \\
\hline Common & & $\begin{array}{l}-1.232 \\
(1.060)\end{array}$ & \\
\hline
\end{tabular}

Notes: Results related to the properties of uncovered interest differentials are presented. The economy-pairs are labeled in the first row. Panel A gives the ADF-GLS ${ }^{\tau}$ and ADF-GLS ${ }^{\mu}$ unit root test results. Figures in square brackets are lag parameters selected by the Bayesian information criterion. Q(6) and Q(12) are the Box-Ljung Q-statistics based on the first six and twelve autocorrelations of the estimated residuals. Panel B gives the persistence of uncovered interest differentials estimated from equation (10). Panel C gives the common and economy-pair (individual) specific trend estimates of the annual average of absolute uncovered interest differentials (equation (12)). Robust standard errors are reported in parentheses underneath coefficient estimates. Significance at the 1,5 and 10\% levels are indicated by “**," "“*," and "\#,, respectively. 
Table 4. Deviations from Relative Purchasing Power Parity

\begin{tabular}{|c|c|c|c|}
\hline & Hong Kong/China & Taiwan/China & Taiwan/Hong Kong \\
\hline \multicolumn{4}{|c|}{ A. Unit root test statistics } \\
\hline ADF-GLS $\mu$ & $-7.802 *[1]$ & $-7.568 *[1]$ & $-3.473 *[4]$ \\
\hline$Q(6)$ & 10.144 & 4.479 & 1.112 \\
\hline $\mathrm{Q}(12)$ & 14.180 & 17.802 & 17.526 \\
\hline ADF-GLS $\tau$ & $-8.025 *[1]$ & $-4.069 *[4]$ & $-3.645 *[4]$ \\
\hline $\mathrm{Q}(6)$ & 7.455 & 0.868 & 1.000 \\
\hline $\mathrm{Q}(12)$ & 9.574 & 15.862 & 17.416 \\
\hline \multicolumn{4}{|l|}{ B. Persistence } \\
\hline $\mathrm{AR}(1)$ & $\begin{array}{c}0.094 \\
(0.116)\end{array}$ & $\begin{array}{c}0.115 \\
(0.116)\end{array}$ & $\begin{array}{c}0.157 \\
(0.120)\end{array}$ \\
\hline $\operatorname{AR}(2)$ & - & - & $\begin{array}{c}0.103 \\
(0.119)\end{array}$ \\
\hline $\operatorname{AR}(3)$ & - & - & $\begin{array}{c}0.189 \\
(0.120)\end{array}$ \\
\hline $\mathrm{AR}(4)$ & - & - & $\begin{array}{c}-0.123 \\
(0.121)\end{array}$ \\
\hline Adjusted $\mathrm{R}^{2}$ & -0.004 & -0.002 & 0.031 \\
\hline \multicolumn{4}{|c|}{ C. Trends in annual absolute averages } \\
\hline Individual & $\begin{array}{c}0.025 \\
(0.160)\end{array}$ & $\begin{array}{l}-1.199 \\
(1.838)\end{array}$ & $\begin{array}{l}-2.428 \\
(2.325)\end{array}$ \\
\hline Common & & $\begin{array}{c}-1.200 \\
(1.010)\end{array}$ & \\
\hline
\end{tabular}

Notes: Results related to the properties of relative purchasing power differentials are presented. The economy-pairs are labeled in the first row. Panel A gives the ADF-GLS ${ }^{\tau}$ and ADF-GLS ${ }^{\mu}$ unit root test results. Figures in square brackets are lag parameters selected by the Bayesian information criterion. Q(6) and Q(12) are the Box-Ljung Q-statistics based on the first six and twelve autocorrelations of the estimated residuals. Panel B gives the persistence of relative purchasing power differentials estimated from equation (10). Panel $\mathrm{C}$ gives the common and economy-pair (individual) specific trend estimates of the annual average of absolute relative purchasing power differentials (equation (12)). Robust standard errors are reported in parentheses underneath coefficient estimates. Significance at the 1,5, and $10 \%$ levels are indicated by “**," "“*," and "\#," respectively. 
Table 5. Summary of the Parity Conditions

\begin{tabular}{|c|c|c|c|}
\hline & Hong Kong/China & Taiwan/China & $\begin{array}{l}\text { Taiwan/Hong } \\
\text { Kong }\end{array}$ \\
\hline \multicolumn{4}{|l|}{ A. Real Interest Parity } \\
\hline stationarity & yes & yes & yes \\
\hline Short-Run Persistence & yes & yes & no \\
\hline Diminishing Trend - individual & no & no & no \\
\hline - common & & yes & \\
\hline \multicolumn{4}{|l|}{ B. Uncovered Interest Parity } \\
\hline stationarity & yes & yes & yes \\
\hline Short-Run Persistence & yes & no & no \\
\hline Diminishing Trend - individual & yes & no & no \\
\hline - common & & no & \\
\hline \multicolumn{4}{|l|}{ C. Relative Purchasing Power Parity } \\
\hline Stationarity & yes & yes & yes \\
\hline Short-Run Persistence & no & no & no \\
\hline Diminishing Trend - individual & yes & no & yes \\
\hline - common & & yes & \\
\hline
\end{tabular}

Note: The Table summarizes the test results reported in Tables 2, 3, and 4. The rows labeled "Stationarity," "Short-Run Persistence," and "Diminishing Trend" correspond to the "Unit root test statistics," "Persistence," and "Trends in absolute annual averages" presented in the preceding tables. The "Diminishing Trend" results under C are based on the results from the extended sample discussed in the text. 
Table 6. Variance Decomposition: Real Interest Differentials

\begin{tabular}{lrcc}
\hline & \multicolumn{1}{c}{$\begin{array}{l}\text { Hong Kong / } \\
\text { China }\end{array}$} & Taiwan / China & \multicolumn{2}{c}{$\begin{array}{l}\text { Taiwan / Hong } \\
\text { Kong }\end{array}$} \\
\hline Var(RID) & 86.818 & 114.100 & 158.727 \\
$\%$ Var(UID) & 16.652 & 626.002 & 436.463 \\
$\%$ Var(RPD) & 66.726 & 686.132 & 606.666 \\
$\%$-2Cov & 16.744 & -1212.134 & -943.130 \\
\hline
\end{tabular}

Notes: The variances of real interest differentials and their decompositions according to

$$
\begin{gathered}
\operatorname{Var}\left(r_{t, k}-r_{t, k}^{*}\right) \equiv \operatorname{Var}\left(i_{t, k}-i_{t, k}^{*}-\Delta s_{t, k}\right)+\operatorname{Var}\left(\pi_{t, k}-\pi_{t, k}^{*}-\Delta s_{t, k}\right) \\
-2 \operatorname{Cov}\left(i_{t, k}-i_{t, k}^{*}-\Delta s_{t, k}, \pi_{t, k}-\pi_{t, k}^{*}-\Delta s_{t, k}\right) .
\end{gathered}
$$

are reported. The economy-pairs are labeled in the first row. "Var(RID)" gives $\operatorname{Var}\left(r_{t, k}-r_{t, k}^{*}\right)$, “\% $\operatorname{Var}(\mathrm{UID}) "$ gives the percentage contribution of $\operatorname{Var}\left(i_{t, k}-i_{t, k}^{*}-\Delta s_{t, k}\right)$, , $\% \operatorname{Var}(\mathrm{RPD})$ " gives the percentage contribution of $\operatorname{Var}\left(\pi_{t, k}-\pi_{t, k}^{*}-\Delta s_{t, k}\right)$, and “\% -2Cov" gives the percentage contribution of the covariance term. 
Table 7. Variance Decomposition: Uncovered Interest Differentials

\begin{tabular}{|c|c|c|c|}
\hline & Hong Kong / China & Taiwan / China & $\begin{array}{l}\text { Taiwan / Hong } \\
\text { Kong }\end{array}$ \\
\hline Var(UID) & 14.349 & 714.270 & 692.786 \\
\hline$\% \operatorname{Var}\left(i-i^{*}\right)$ & 95.286 & 1.303 & 0.479 \\
\hline$\% \operatorname{Var}(\Delta s)$ & 3.791 & 97.400 & 101.027 \\
\hline$\%-2 \mathrm{Cov}$ & 0.922 & 1.295 & -1.506 \\
\hline
\end{tabular}

Note: The variances of real interest differentials and their decompositions according to

$$
\operatorname{Var}\left(i_{t, k}-i_{t, k}^{*}-\Delta s_{t, k}\right) \equiv \operatorname{Var}\left(i_{t, k}-i_{t, k}^{*}\right)+\operatorname{Var}\left(\Delta s_{t, k}\right)-2 \operatorname{Cov}\left(i_{t, k}-i_{t, k}^{*}, \Delta s_{t, k}\right)
$$

are reported. The economy-pairs are labeled in the first row. "Var(UID)" gives

$\operatorname{Var}\left(i_{t, k}-i_{t, k}^{*}-\Delta s_{t, k}\right), " \% \operatorname{Var}\left(i-i^{*}\right)$ " gives the percentage contribution of $\operatorname{Var}\left(i_{t, k}-i_{t, k}^{*}\right), " \% \operatorname{Var}($ $\Delta s)$ " gives the percentage contribution of $\operatorname{Var}\left(\Delta s_{t, k}\right)$, and “\% $\%$-2 Cov" gives the percentage contribution of the covariance term. 
Table 8. Variance Decomposition: Relative Purchasing Power Parity Differentials

\begin{tabular}{|c|c|c|c|}
\hline & $\begin{array}{l}\text { Hong Kong / } \\
\text { China }\end{array}$ & Taiwan / China & $\begin{array}{l}\text { Taiwan / Hong } \\
\text { Kong }\end{array}$ \\
\hline $\operatorname{Var}(\mathrm{RPD})$ & 57.931 & 782.878 & 962.943 \\
\hline$\% \operatorname{Var}\left(\pi-\pi^{*}\right)$ & 98.950 & 14.086 & 15.528 \\
\hline$\% \operatorname{Var}(\Delta s)$ & 0.939 & 88.864 & 72.683 \\
\hline$\%-2 \mathrm{Cov}$ & 0.110 & -2.950 & 11.787 \\
\hline
\end{tabular}

Note: The variances of relative purchasing power parity differentials and their decompositions according to

$$
\operatorname{Var}\left(\pi_{t, k}-\pi_{t, k}^{*}-\Delta s_{t, k}\right) \equiv \operatorname{Var}\left(\pi_{t, k}-\pi_{t, k}^{*}\right)+\operatorname{Var}\left(\Delta s_{t, k}\right)-2 \operatorname{Cov}\left(\pi_{t, k}-\pi_{t, k}^{*}, \Delta s_{t, k}\right)
$$

are reported. The economy-pairs are labeled in the first row. "Var(RPD)" gives $\operatorname{Var}\left(\pi_{t, k}-\pi_{t, k}^{*}-\Delta s_{t, k}\right), " \% \operatorname{Var}\left(\pi-\pi^{*}\right)$ " gives the percentage contribution of $\operatorname{Var}\left(\pi_{t, k}-\pi_{t, k}^{*}\right)$, "\% $\operatorname{Var}(\Delta s) "$ gives the percentage contribution of $\operatorname{Var}\left(\Delta s_{t, k}\right)$, and "\% $\%$ - $\operatorname{Cov"~gives~the~}$ percentage contribution of the covariance term. 
Figure 1. Real Interest Differentials

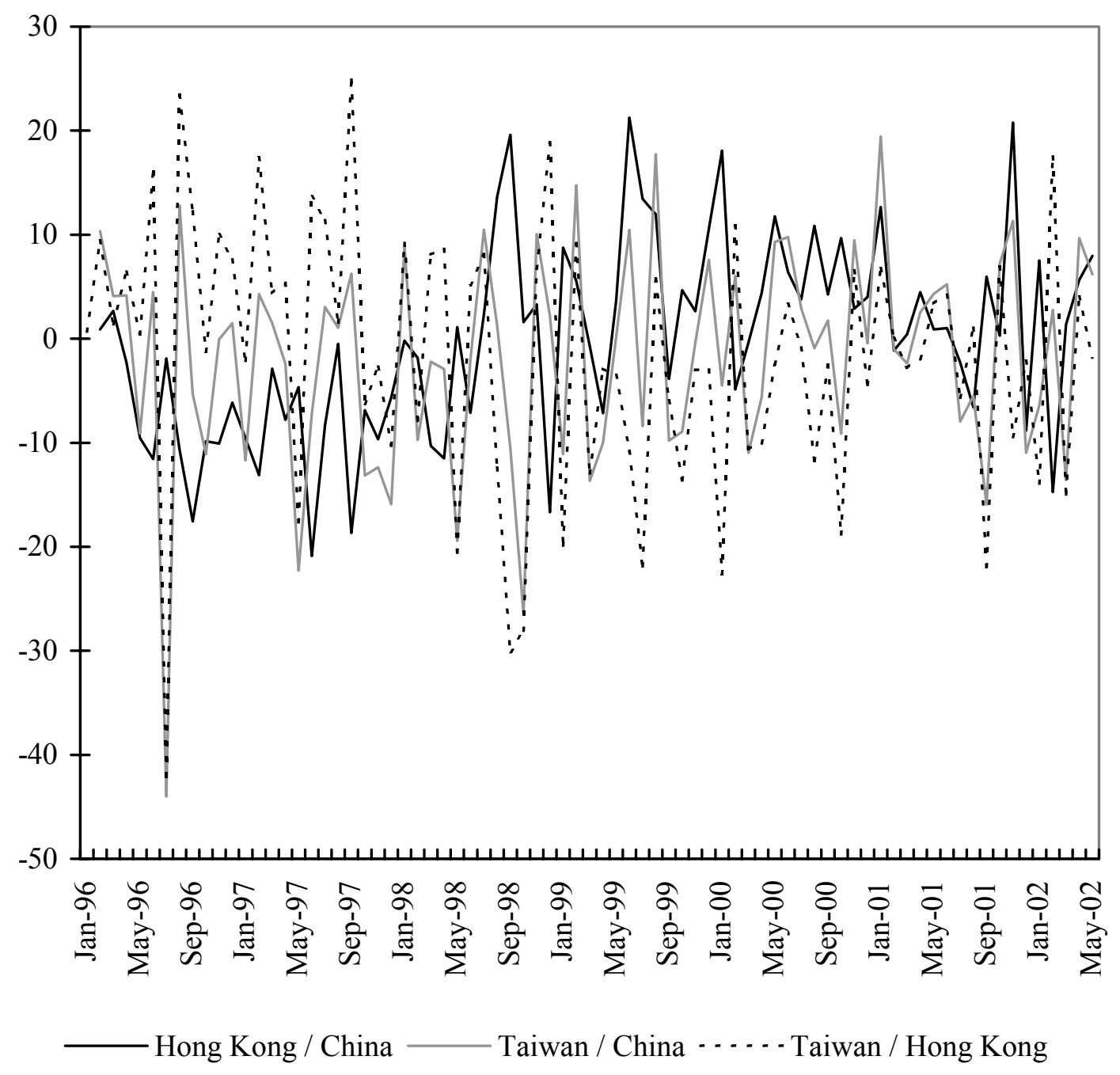


Figure 2. Uncovered Interest Differentials

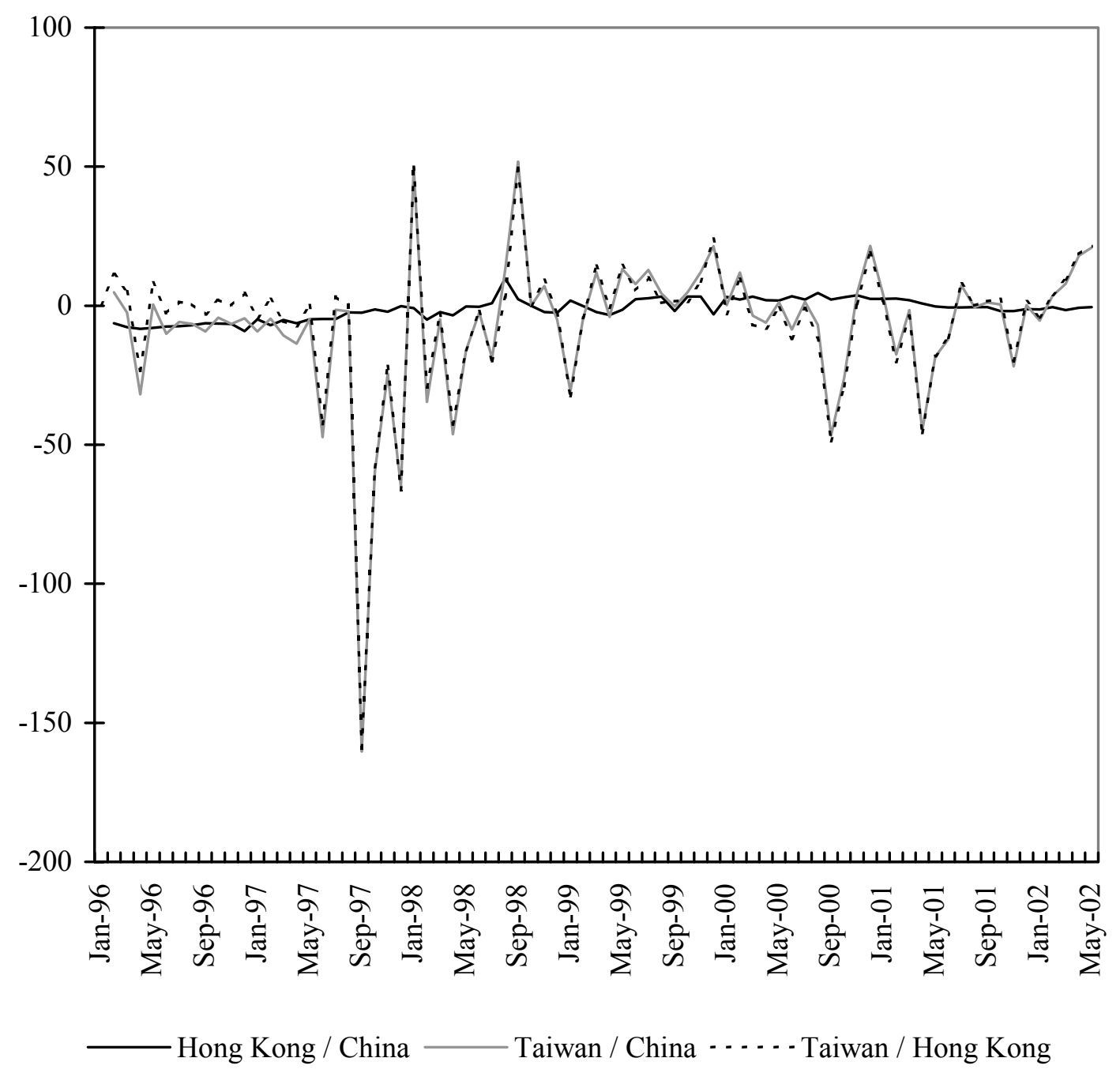


Figure 3. Deviations from Relative Purchasing Power Parity

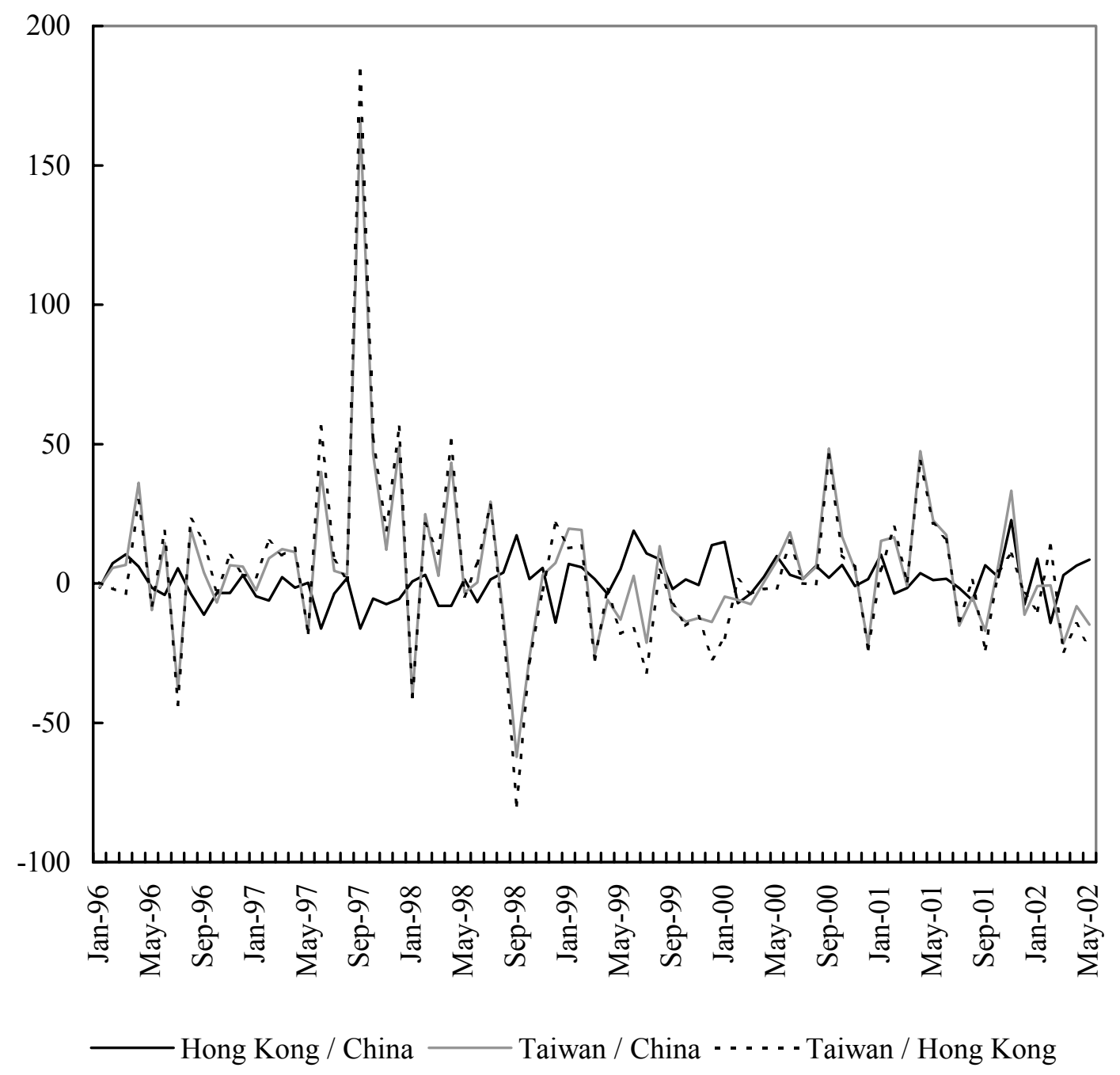

